\title{
Long-Term Endocrine Function in Hypercholesterolemic Patients Treated With Pravastatin, a New 3-Hydroxy-3-Methylglutaryl Coenzyme A Reductase Inhibitor
}

\author{
Adrian S. Dobs, P. Sankara Sarma, and David Schteingart
}

\begin{abstract}
Steroid hormone production within the gonads and adrenals requires a continuous supply of cholesterol derived from de novo synthesis within the gland and from uptake of circulating plasma lipoproteins. Steroid hormone secretion was prospectively studied over 24 months in 64 hypercholesterolemic subjects (group l, aged $52 \pm 1$ years [mean \pm SEM], 61\% male) participating in a randomized double-blind clinical trial of pravastatin (20 to $80 \mathrm{mg}$ daily), a new 3-hydroxy-3-methylglutaryl coenzyme $A$ (HMG-CoA) reductase inhibitor, compared with patients taking cholestyramine or other lipid-lowering drugs (group II). Attempts were made in both groups to maintain serum low-density lipoprotein cholesterol (LDL-C) levels between the 25 th and 50th percentile for age and gender. At 24 months, serum LDL-C level decreased by $42 \% \pm 3 \%$ in group I and $44 \% \pm 1 \%$ in group II $(\boldsymbol{P}<.001 v$ baseline, NS between groups). Basal secretion of cortisol, aldosterone, and dehydroepiandrostenedione sulfate (DHEA-S) was maintained throughout the study. However, the serum DHEA-S secretory response to Cortrosyn (Organon, West Orange, NJ) diminished in both treatment groups at 6 and 12 months $(P<.05)$. In men, basal serum testosterone levels and the testosterone response to human chorionic gonadotropin (HCG) did not change. There was some diminution of sperm motility noted in both treatment groups at 6 and 12 months in the subset of men undergoing semen analysis $(n=14, P<.05)$. In conclusion, pravastatin had no significant effect on steroid metabolism. Changes noted in DHEA-S were not specific for pravastatin, suggesting that this impairment is related to lipid-lowering effects.
\end{abstract}

Copyright 11993 by W.B. Saunders Company

C OMPLIANCE WITH the National Cholesterol Education Program Adult Treatment Guidelines ${ }^{1}$ will permit large segments of the population to be treated for hypercholesterolemia over extended periods of time. The 3-hydroxy-3-methylglutaryl coenzyme A ( $\mathrm{HMG}-\mathrm{COA}$ ) reductasc inhibitors arc a new class of lipid-lowering agents that offer an effective and relatively safe intervention for the treatment of hypercholesterolemia. An example of this class of drugs is lovastatin, which is found to produce $30 \%$ to $40 \%$ reductions in low-density lipoprotein cholesterol (LDL-C) levels. ${ }^{2-4}$ Pravastatin, another drug of this type with comparable lipid-lowering efficacy, ${ }^{5}$ is structurally similar, but its tissue specificity may vary ${ }^{6,7}$ Few side effects have been reported with either lovastatin or pravastatin.

The possibility that inhibition of cholesterol synthesis may interfere with adrenal cortical and gonadal function is a concern for patients treated with these drugs. Lipidlowering agents may impair steroid hormone synthesis directly hy decreasing the availability of circulating cholesterol for endocrine gland uptake (common to all hypolipidemic drugs) or diminishing in situ cholesterol synthesis (specific for HMG-CoA reductase inhibitors), or indirectly in the case of the gonads by altering levels of dolichol

From the Department of Medicine, The Johns Hopkins University School of Medicine, Baltimore, $M D$; and the Department of Medicine, University of Michigan School of Medicine, Ann Arbor, MI.

Submitted January 11, 1992; accepted October 21, 1992.

Supported in part by National Institutes of Health Grant No. NOIAI32520 to the Outpatient Clinical Research Center, The Johns Hopkins University School of Medicine, and by Bristol-Myers Squibb, Princeton, NJ.

Presented in part at the 1989 Eastem Region American Federation of Clinical Research.

Address reprint requests to Adrian S. Dobs, MD, $600 \mathrm{~N}$ Wolfe St,

Blalock 906B, The Johns Hopkins Hospital, Baltimore, MD 21205.

Copyright 1993 by W.B. Saunders Company

0026-0495/93/4209-0013\$03.00/0 phosphate, a lipid-carrier molecule required for glycosylation of gonadotropins. ${ }^{8}$

In cultured human fetal adrenal cortical cells, the majority of cholesterol was obtained via the LDL receptor pathway. ${ }^{9}$ Subjects with heterozygous familial hypercholesterolemia have normal basal cortisol concentrations but attenuated cortisol responses to corticotropin administration. ${ }^{10}$ In the basal state, enhanced in situ cholesterol biosynthesis may compensate for defective uptake of LDL." "] Studies in small groups of genetically mixed hypercholesterolemic patients treated with lovastatin demonstrated variable effects on adrenal steroid hormone secretion. ${ }^{12-14}$ Peak cortisol secretion was blunted after corticotropin administration in 24 patients treated for 8 weeks with simvastatin. ${ }^{14}$ Plasma aldosterone levels were within normal limits, but reduced after 9 months of simvastatin. ${ }^{15}$

Although in vitro basal and human chorionic gonadotropin (HCG)-stimulated testosterone production in rat Leydig cells was impaired with short-term lovastatin administration, ${ }^{15}$ serum testosterone levels were maintained in a clinical trial using lovastatin. ${ }^{16}$ Degeneration of seminiferous epithelium in the testes has been observed in dogs receiving lovastatin $20 \mathrm{mg} / \mathrm{kg}$ per day. ${ }^{11}$ Hyperlipidemic men maintained their serum levels of gonadotropins and semen analyses after 4 months of treatment with either neomycin or lovastatin. ${ }^{8}$ Recently in a study of porcine ovarian theca cells, lovastatin was noted to have an additional inhibitory action at the level of the 17-hydroxylase:C17,20-lyase complex, resulting in decreased androstenedione production. ${ }^{17}$ The present study was undertaken to determine the effects of long-term use of pravastatin, a new HMG-CoA reductase inhibitor, on adrenal and gonadal function in men and women.

\section{SUBJECTS AND METHODS}

\section{Subjects}

Men and postmenopausal or surgically sterile women aged 21 to 70 were selected; they were recruited from newspaper advertise- 
ments and publicized screenings to measure serum cholesterol. Subjects qualified for randomization into active treatment if they had three consecutive fasting serum LDL-C levels greater than both $160 \mathrm{mg} / \mathrm{dL}$ and the 75 th percentile for age and $\operatorname{sex}^{18}$ after at least 6 weeks of dietary compliance. Serum triglyceride levels were lower than $250 \mathrm{mg} / \mathrm{dL}$ in all subjects. Patients were excluded if they had evidence of endocrine, renal, or hepatic disease, diabetes mellitus (fasting blood glucose $>140 \mathrm{mg} / \mathrm{dL}$ ), or unstable cardiac disease.

\section{Studv Design}

Pravastatin was used in a double-blind placebo-controlled clinical trial at four centers within the United States (Fig 1). All subjects received a Step 1 American Heart Association lipidlowering $\operatorname{diet}^{1{ }^{19}}$ for at least 6 weeks before randomization. The diet was maintained throughout the study, ${ }^{71}$ and patients had regular follow-up visits with a dietitian to evaluate and reinforce dietary compliance. A 4-week placebo lead-in period was included before randomization during the diet phase. Patients were randomized to receive either pravastatin (group I) or other hypocholesterolemic drugs (group II; predominantly cholestyramine). During the first 6 mont is of the study. group I patients received pravastatin $40 \mathrm{mg}$ daily plus placebo cholestyramine powder; group II patients received cholestyramine $16 \mathrm{~g}$ daily plus placebo tablets. Ten subjects were taking only a placebo tablet for the first 4 months. Ihese patients were then rerandomized to an active treatment grour.

After 6 months, lipid-lowering medications could be adjusted in both groups to maintain serum LDL levels between the 25th and 50 th percentile for age and sex. ${ }^{18}$ In group I, the placebo powder was discontinued at 6 months and pravastatin could be increased up to $80 \mathrm{mg}$ daily; after 1 year, cholestyramine could be added to the treatment regimen for group I subjects. In group II, the placebo tablet for pravastatin was continued throughout the study period; five patients in Group II were allowed to start niacin or probucol treatrient. Thus, throughout the study, subjects were treated with

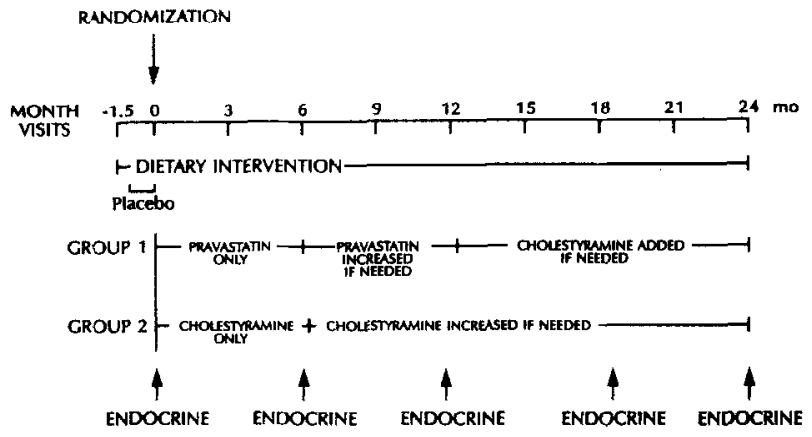

Fig 1. Study design. In the prerandomization phase, dietary intervention alone occurred between month -1.5 and 0 . A placebo lead-in phase occurred in month -1 . Patients were then randomized to a double-blind clinical trial in group I (pravastatin $\mathbf{4 0} \mathrm{mg}$ daily) or group II (cholestyramine up to $16 \mathrm{~g}$ daily) for 6 months. In group I, after 6 months pravastatin dosage could be increased to $80 \mathrm{mg}$ daily and after 12 months cholestyramine could be added to maintain serum LDL-C levels between the 25 th and 50 th percentile ${ }^{18}$ for gender- and age-matched controls. In group II, cholestyramine dosage could be increased to $32 \mathrm{~g}$ daily after 6 months to maintain serum LDL-C levels at levels comparable to those in group $I$. Ten subjects were taking only a placebo tablet for the first 4 months and were then rerandomized to an active treatment group. Five patients in group II were allowed to start niacin or probucol treatment. Endocrine testing was performed $0,6,12,18$, and 24 months after randomization. varying doses - pravastatin or cholestyramine depending on their serum lipid $\mathrm{CO}_{2}$. entrations. The study was approved by The Johns Hopkins Medici Institutions Review Board: all patients gave informed consent.

\section{Endocrine Testing}

Hormone studies were performed at baseline and $6,12,18$, and 24 months after randomization. For evaluating adrenal cortical function, cortisol, aldosterone, and dehydroepiandrostenedione sulfate (DHEA-S) levels were measured before and 30,60 , and 90 minutes after intravenous administration of $250 \mu \mathrm{g}$ synthetic corticotropin (Cortrosyn, Organon, West Orange, NJ); basal corticotropin and renin levels were also measured.

Gonadal function was evaluated by measuring basal levels of serum progesterone, prolactin, follicle-stimulating hormone (FSH), luteinizing hormone ( $\mathrm{LH})$, total and free testusterone, and estradiol. In a subset of men, a semen analysis was obtained and serum testosterone level was measured 24 and 48 hours after intramuscular injection of HCG 2,500 IU. All blood was obtained between the hours of 8:00 and 10:00 AM and immediately centrifuged; serum was shipped on dry ice to a central laboratory where all samples were assayed. One semen sample was obtained at each time point from participants from Iohns Hopkins University and the University of Michigan after a period of abstinence of 3 days. Significant illnesses during the previous 3 months were documented. Men were recruited into the study over a 1-year period, thus permitting serum samples to be collected through all seasons. Semen analyses were performed within 2 hours of obtaining the sample by a dedicated technician for each site (with a second one available for vacations, etc.) in the following manner. Density was determined manually using a counting chamber, and percent motility was reported after a manual observation of 200 sperm. Criteria for normal sperm morphology were determined manually by the presence of a sheath, head, and a single tail. A nigrosin-eosinophil stain was performed to determine the viability of the sperm; the degree of dye uptake correlates with the percent normal morphology.

\section{Assays}

All hormone measurements were performed by radioimmunoassay; all individual samples were assayed in the same assay. All steroid hormone levels (cortisol [sensitivity, $0.2 \mu \mathrm{g} / \mathrm{dL}$ ], aldosterone [sensitivity, $16.0 \mathrm{pg} / \mathrm{mL}$ ], DHEA-S [sensitivity, $2.1 \mu \mathrm{g} / \mathrm{dL}$ ], progesterone [sensitivity, $0.05 \mathrm{ng} / \mathrm{mL}$ ], estradiol [sensitivity, 8.0 $\mathrm{pg} / \mathrm{mL}$ ]. and total and free testosterone [sensitivity, $110 \mu \mathrm{g} / \mathrm{dL}$ ]) were measured by solid-phase radioimmunoassay ( $\mathrm{I}-125$ radioimmunoassay Coat-A-Count Kit method, Diagnostic Product Corp, Los Angeles, CA). Interassay and intraassay coefficients of variation ranged from $5 \%$ to $8 \%$. Total cholesterol, high-density lipoprotein (HDL) cholesterol, and triglycerides (TG) were analyzed using microenzymatic procedures on a Hitachi autoanalyzer model 705 (BMD, Indianapolis. IN) as previously described. ${ }^{21}$ HDL-C was isolated using the modified Lipid Research Clinics procedure (heparin-2 mol/L manganese chloride). ${ }^{22} \mathrm{LDL}-\mathrm{C}$ level was calculated from the Friedewald formula. ${ }^{23}$

\section{Statistical Analysis}

Statistical analysis was performed using Statistical Analysis Systems (SAS Institute, Cary, NC) on a mainframe computer and CLINFO in The Johns Hopkins University School of Hygiene and Public Health. Data were analyzed using two approaches. In the first, all subjects were grouped as a whole without distinction for treatment assignment. In the second, patients were classified into 
Table 1. Baseline Characteristics of Subjects in Group 1 (pravastatin-treated) and Group II (other lipid-lowering agents)

\begin{tabular}{lrrr}
\hline & Group i & Group II & \multicolumn{1}{c}{ Total } \\
\hline Total subjects (\% male) & $43(63)$ & $21(43)$ & $54(61)$ \\
Age $(\mathrm{yr})$ & 53.12 & 51.33 & 52.53 \\
SEM & 1.67 & 2.12 & 1.31 \\
Total cholesterol $(\mathrm{mg} / \mathrm{dL})$ & 281.45 & 258.05 & 273.65 \\
SEM & 9.17 & 13.84 & 7.72 \\
Range & $173-411$ & $186-442$ & $156-442$ \\
LDL $(\mathrm{mg} / \mathrm{dL})$ & 223.14 & 206.33 & 217.63 \\
SEM & 6.46 & 10.63 & 5.61 \\
Range & $140-335$ & $162-377$ & $140-377$ \\
\hline
\end{tabular}

two treatment groups (group I = pravastatin with or without other lipid-lowering agents, group II = other lipid-lowering agents without pravastatin). Data from the one premenopausal woman in the study was excluded in analyzing female gonadal function. Sample sizes were calculated to detect a difference in serum testosterone levels of at least $30 \%$ between groups at 12 months with a power of 0.8 and an $\alpha$ of .05 .

Data are presented as means \pm standard error of the mean. The null hypothesis was rejected at a $P$ value of less than .05 . Statistical tests included paired or unpaired Student's $t$ test and repeatedmeasures ANOVA. For those variables analyzed by the ANOVA model, we assessed the effect of treatment group, month of testing, and their interaction. Corticotropin- and HCG-stimulation tests were analyzed by evaluating the area under the response curve and the peak $\delta$ (maximum serum level minus basal concentration) response. Men and women were analyzed separately for serum total and free testosterone, estradiol, progesterone, FSH, and LH determinations.

\section{RESULTS}

\section{Baseline Characteristics}

Sixty-four hypercholesterolemic subjects (aged $52 \pm 1$ years, $61 \% \mathrm{mcn} ; 92 \%$ of the women postmenopausal) participated in a prospective endocrine evaluation during the first year of the clinical trial; a subset of 10 patients continued for 24 months. There were no statistically significant differences in baseline age, gender distribution, or total serum cholesterol or LDL-C concentrations between the two groups at initiation of the study (Table 1). At 24 months, LDL-C levels decreased by $42 \% \pm 3 \%$ in group I and $44 \% \pm 1 \%$ in Group II $(P<.001 v$ baseline, NS between groups). Drug dosages were altered to maintain serum LDL-C concentrations between the 25th and 50th percentile for age and gender. ${ }^{18}$ Based on tablet counts at each visit, there was a $93 \%$ compliance rate in both groups.

\section{Effects on Adrenal Function}

DHEA-S. Mcan basal scrum DHEA-S levels did not change significantly in either group (Table 2). In contrast, the DHEA-S response (peak - basal levels) to Cortrosyn administration decreased in patients tested at 6 months ( $\mathrm{n}=46$; paired Student's $t$ test, $P<.05$ ) and 12 months ( $\mathrm{n}=41$; paired Student's $t$ test, $P<.05$ ) compared with the DHEA-S response observed at the start of the study (Fig 2A). This diminished secretory response was similar in both groups and was unrelated to the decrease in total cholesterol levels at those lime points. In a subset of participants $(n=8)$ evaluated at 18 months, the serum DHEA-S response to intravenous corticotropin increased to levels similar to those observed before initiation of drug treatment. Because only one of these patients was in group II, a group comparison cannot be performed.

Cortisol. Mean basal cortisol levels remained constant in all subjects regardless of treatment assignment (Table 2). Similarly, mean basal serum corticotropin levels did not change. The serum cortisol response to corticotropin at 0,6 , 12 , or 18 months did not change with treatment (Fig 2B).

Aldosterone. Without distinction for treatment assignment, the mean basal concentration of aldosterone at 12

Table 2. Adrenal Function: Basal Serum Hormone Concentrations for Men and Women in Group I (pravastatin-treated) and Group II (other lipid-lowering agents) at $0,6,12,18$, and 24 Months

\begin{tabular}{|c|c|c|c|c|c|c|c|c|c|c|c|c|c|c|c|}
\hline & \multicolumn{15}{|c|}{ Months } \\
\hline & \multicolumn{3}{|c|}{0} & \multicolumn{3}{|c|}{6} & \multicolumn{3}{|c|}{12} & \multicolumn{3}{|c|}{18} & \multicolumn{3}{|c|}{24} \\
\hline & 1 & ॥ & Total & 1 & $\|$ & Total & 1 & $\|$ & Total & 1 & II & Total & 1 & $\|$ & Total \\
\hline \multicolumn{16}{|c|}{ DHEA-S $(\mu \mathbf{g} / \mathrm{dL})$} \\
\hline Mean & 101.6 & 123.1 & 108.7 & 121.8 & 142.3 & 128.4 & 101.1 & 135.6 & 113.2 & 66.1 & 49.9 & 108.0 & 89.0 & 172.0 & 130.0 \\
\hline \pm SEM & 12.6 & 23.1 & 11.3 & 13.5 & 28.6 & 12.9 & 13.2 & 19.6 & 11.1 & 23.5 & - & 42.3 & & & 42.0 \\
\hline \multicolumn{16}{|c|}{ Cortisol $(\mu \mathrm{g} / \mathrm{dL})$} \\
\hline Mean & 14.3 & 13.0 & 13.9 & 13.9 & 14.1 & 14.0 & 12.3 & 13.6 & 12.8 & 13.9 & 15.6 & 5.0 & 12.1 & 14.5 & 13.0 \\
\hline \pm SEM & 0.9 & 0.8 & 0.7 & 0.8 & 0.7 & 0.6 & 0.7 & 0.9 & 0.5 & 1.4 & - & .9 & & & 1.2 \\
\hline \multicolumn{16}{|c|}{ Corticotropin (pg/mL) } \\
\hline Mean & 69.0 & 49.4 & 62.6 & 48.7 & 42.6 & 46.8 & 48.2 & 35.1 & 43.6 & - & - & - & 80.0 & 60.0 & 70.0 \\
\hline \pm SEM & 7.6 & 6.9 & 5.7 & 4.5 & 7.1 & 3.8 & 4.8 & 4.1 & 3.5 & - & - & 一 & - & - & 14.0 \\
\hline \multicolumn{16}{|c|}{ Aldosterone (ng/dL) } \\
\hline Mean & 8.7 & 7.6 & 8.3 & 8.6 & 7.5 & 8.2 & 9.9 & 11.9 & $10.6^{*}$ & 9.1 & 5.8 & 7.0 & 10.1 & 21.4 & 16.0 \\
\hline \pm SEM & .8 & 1.3 & 0.7 & 0.8 & 1.0 & 0.6 & 1.1 & 2.5 & 1.1 & 1.5 & - & 1.7 & - & - & 6.0 \\
\hline \multicolumn{16}{|c|}{$\operatorname{Renin}(\mathrm{ng} / \mathrm{mL} / \mathrm{h})$} \\
\hline Mean & 2.72 & 3.83 & 3.07 & 2.54 & 2.14 & 2.39 & 6.17 & 3.11 & 5.40 & 10.06 & 6.09 & 8.2 & - & - & - \\
\hline \pm SEM & 0.24 & 0.61 & 0.26 & 0.25 & 0.37 & 0.21 & 3.45 & 0.88 & 2.59 & 2.35 & - & 2.0 & 一 & - & - \\
\hline$N$ & 43 & 21 & 64 & 40 & 19 & 59 & 35 & 19 & 54 & 9 & 1 & 10 & 1 & 1 & 2 \\
\hline
\end{tabular}

NOTE. All data are means \pm SEM.

${ }^{*} P<.05$ for all patients as a whole at 12 months. 

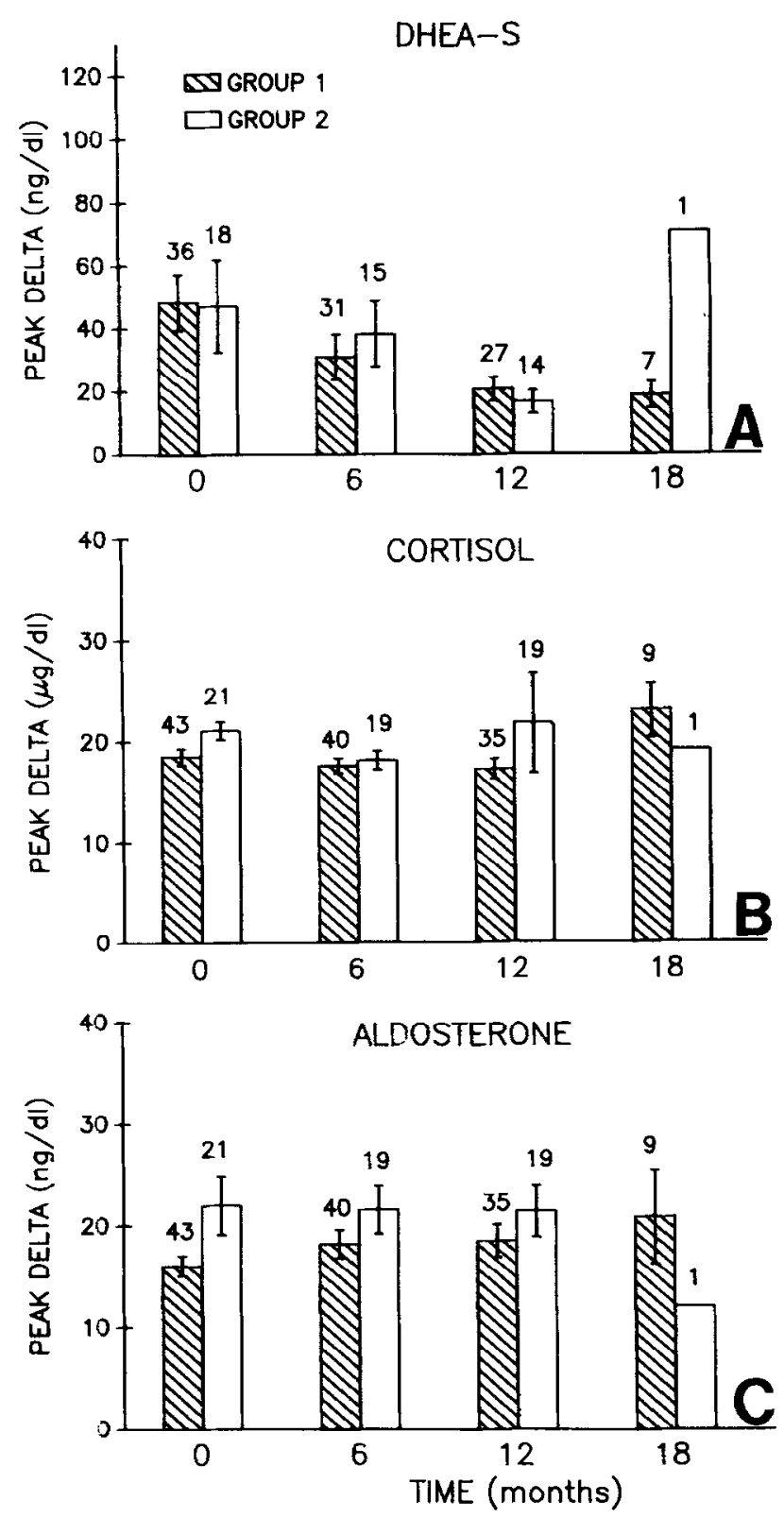

Fig 2. Maximum delta adrenal steroid response to $250 \mu \mathrm{g}$ intravenous Cortrosyn (corticotropin). Peak delta (maximum response minus basal concentration) plasma DHEA-S (A), cortisol (B), and aldosterone (C) responses were measured after administration of Cortrosyn.

months was significantly higher $(10.6 \pm 1.5 \mu \mathrm{g} / \mathrm{dL})$ than that observed at baseline $(8.3 \pm 0.7 \mu \mathrm{g} / \mathrm{dL}, P<.01)$. However, basal concentrations $(8.8 \pm 1.4 \mu \mathrm{g} / \mathrm{d}, \mathrm{n}=10) \mathrm{re}_{-}$ turned to baseline by 18 months (Table 2). Although a between-group comparison could not be performed at 18 months because of a small sample size, the aldosterone response to corticotropin administration did not change over the 18-month period (Fig 2C).

\section{Effects on Gonadal Function}

There were no statistically significant differences in mcan basal levels of total or free testosterone, FSH, LH, estradiol, or progesterone over a period of 24 months for either men or postmenopausal women (Tables 3 and 4). Only one woman was premenopausal, and there were no statistically significant changes in her serum levels (data not shown). Among the men, 28 subjects $(72 \%)$ showed a decrease in basal total testosterone levels at 12 months regardless of treatment assignment; however, these changes were not statistically significant.

A subset of 10 men with a mean age (48 \pm 4 years) similar to that of the group as a whole received an HCG stimulation test and semen analysis; only data through 12 months are presented since the sample sizes were small at 18 and 24 months. Total (Fig 3A) and free testosterone (Fig $3 \mathrm{~B}$ ) response (peak - basal levels) to the administration of HCG did not change with treatment during 24 months of follow-up evaluation. A decrease in mean semen volume and sperm count was observed at 6 months $(P<.05)$ in all men regardless of treatment assignment; values returned toward baseline by 12 months. Mean sperm motility decreased in men from both groups at 6 and 12 months $(P<.05)$. No differences were noted in these variables between group I and group II (Fig 4).

\section{DISCUSSION}

We sought to compare the long-term effects of decreasing LDL-C levels on steroid hormone metabolism using an HMG-CoA reductase inhibitor. In our patients studied over 2 years, basal cortisol and DHEA-S levels did not change with pravastatin use. The increase in basal aldosterone levels at 12 months $(P<.05)$ was not specific for pravastatin, since it was observed in subjects regardless of treatment assignment. The secretory reserve of cortisol and aldosterone, as determined by a Cortrosyn stimulation test, was maintained throughout the study. However, the capacity.to stimulate DHEA-S secretion in response to corticotropin decreased in subjects from both groups regardless of treatment assignment. Thus this occurred even with cholestyramine, which does not affect de novo synthesis of cholesterol within the adrenal gland. This finding is difficult to interpret and is probably clinically insignificant, since DHEA-S has such a long serum half-life.

In this study, men and postmenopausal women maintained basal sex hormone secretion throughout the 2 years. Possible detrimental effects on premenopausal women cannot be excluded from this investigation. Obviously, it would be unlikely to detect changes in serum progesterone levels, since this hormone is secreted in such low concentrations in postmenopausal women. Semen analyses obtained in a subset of men showed reductions in sperm count, motility, and percent normal sperm over the course of 2 years in men in both groups. There were no differences noted between those men treated with pravastatin versus those treated with other lipid-lowering agents. Although patients were given strict instructions on how to obtain fresh samples, semen analyses can be difficult to interpret, especially since there is considerable variation for individual semen specimens from the same subject. Sexual function was not adcquately investigatcd.

The lack of effect of pravastatin compared with resin on steroid hormone metabolism that we observed in this study 
Table 3. Gonadal Functions: Basal Serum Hormone Concentrations for Women in Group I (pravastatin-treated) and Group II (other lipid-lowering agents) at 0,6 , and 12 Months

\begin{tabular}{|c|c|c|c|c|c|c|c|c|c|}
\hline & \multicolumn{9}{|c|}{ Months } \\
\hline & \multicolumn{3}{|c|}{0} & \multicolumn{3}{|c|}{6} & \multicolumn{3}{|c|}{12} \\
\hline & 1 & II & Total & 1 & $\|$ & Total & 1 & II & Total \\
\hline \multicolumn{10}{|l|}{ Females } \\
\hline \multicolumn{10}{|c|}{ Testosterone } \\
\hline \multicolumn{10}{|c|}{ Total $(\mathrm{ng} / \mathrm{dL})$} \\
\hline Mean & 15.3 & 12.0 & 14.2 & 19.2 & 11.2 & 16.4 & 18.8 & 25.4 & 21.1 \\
\hline +SEM & 2.0 & 2.0 & 2.0 & 4.0 & 1.0 & 3.0 & 2.0 & 9.0 & 4.0 \\
\hline \multicolumn{10}{|c|}{ Free $(\mathrm{pg} / \mathrm{mL})$} \\
\hline Mean & 0.5 & 0.6 & 0.5 & 0.5 & 0.6 & 0.5 & 0.4 & 0.7 & 0.6 \\
\hline \pm SEM & 0.1 & 0.2 & 0.1 & 0.2 & 0.2 & 0.1 & 0.1 & 0.4 & 0.2 \\
\hline \multicolumn{10}{|c|}{$\mathrm{FSH}(\mathrm{mlU} / \mathrm{mL})$} \\
\hline Mean & 37.3 & 30.3 & 34.8 & 34.9 & 29.1 & 32.9 & 37.7 & 33.6 & 36.0 \\
\hline \pm SEM & 4.1 & 3.5 & 2.9 & 4.2 & 2.5 & 2.9 & 4.9 & 4.1 & 3.3 \\
\hline \multicolumn{10}{|c|}{$\mathrm{LH}(\mathrm{mlU} / \mathrm{mL})$} \\
\hline Mean & 34.8 & 33.4 & 34.3 & 37.5 & 39.7 & 38.3 & 35.6 & 32.5 & 34.4 \\
\hline \pm SEM & 3.3 & 4.6 & 2.6 & 4.3 & 4.6 & 3.2 & 4.7 & 4.7 & 3.3 \\
\hline \multicolumn{10}{|c|}{ Estradiol $(\mathrm{pg} / \mathrm{mL})$} \\
\hline Mean & 24.6 & 30.9 & 26.9 & 13.3 & 16.9 & 14.5 & 17.1 & 20.5 & 18.4 \\
\hline$\pm \mathrm{SEM}$ & 10.3 & 15.5 & 8.5 & 2.3 & 8.1 & 3.1 & 6.0 & 6.1 & 4.3 \\
\hline \multicolumn{10}{|c|}{ Progesterone $(\mathrm{ng} / \mathrm{dL})$} \\
\hline Mean & 0.19 & 0.39 & 0.26 & 0.19 & 0.15 & 0.18 & 0.17 & 0.19 & 0.18 \\
\hline \pm SEM & 0.03 & 0.22 & 0.08 & 0.03 & 0.02 & 0.02 & 0.03 & 0.04 & 0.02 \\
\hline $\mathrm{N}$ & 16 & 9 & 25 & 15 & 8 & 23 & 12 & 8 & 20 \\
\hline
\end{tabular}

NOTE. All data are means $\pm \mathrm{SEM}$.

may be a function of the pravastatin dose or tissue specificity. It is unlikely that drug dosage would have an effect, since subjects varied their drug dosages throughout the study depending on their serum lipid levels. Although there is no evidence for this, perhaps at abnormally low levels of serum lipids there may be harmful effects on steroid synthesis. The study subjects were at best brought into the normal range.

Tabłe 4. Gonadal Function. Basal Serum Hormone Concentrations for Men in Group I (pravastatin-treated) and Group II (other lipid-lowering agents) at $0,6,12,18$, and 24 Months

\begin{tabular}{|c|c|c|c|c|c|c|c|c|c|c|c|c|c|c|c|}
\hline & \multicolumn{15}{|c|}{ Months } \\
\hline & \multicolumn{3}{|c|}{0} & \multicolumn{3}{|c|}{6} & \multicolumn{3}{|c|}{12} & \multicolumn{3}{|c|}{18} & \multicolumn{3}{|c|}{24} \\
\hline & 1 & II & Total & I & II & Total & 1 & ॥I & Total & 1 & II & Total & 1 & II & Total \\
\hline \multicolumn{16}{|l|}{ Males } \\
\hline \multicolumn{16}{|c|}{ Testosterone } \\
\hline \multicolumn{16}{|c|}{ Total (ng/dL) } \\
\hline Mean & 504.0 & 518.0 & 508.0 & 501.2 & 511.0 & 504.0 & 460.0 & 431.0 & 450.0 & 600.0 & 570.0 & 589.0 & 355.0 & 290.0 & 355.0 \\
\hline $\pm S E M$ & 26.0 & 26.0 & 20.0 & 36.0 & 38.0 & 27.0 & 60.0 & 24.0 & 41.0 & 121.0 & - & 10.0 & 5.0 & - & 5.0 \\
\hline \multicolumn{16}{|c|}{ Free $(\mathrm{pg} / \mathrm{mL})$} \\
\hline Mean & 17.2 & 16.0 & 16.8 & 16.8 & 16.6 & 16.7 & 15.6 & 17.1 & 16.1 & 16.8 & 1.7 & 6.8 & 13.6 & 19.2 & 13.6 \\
\hline $\pm S E M$ & 0.8 & 1.0 & 0.6 & 1.5 & 1.5 & 1.1 & 1.0 & 1.3 & 0.8 & 5.6 & - & 3.2 & .2 & - & .01 \\
\hline \multicolumn{16}{|c|}{$\mathrm{FSH}(\mathrm{mlU} / \mathrm{mL})$} \\
\hline Mean & 4.8 & $4: 1$ & 4.6 & 3.8 & 3.6 & 3.8 & 11.2 & 4.0 & 8.8 & 7.0 & 4.8 & 5.9 & 9.7 & 8.3 & 9.0 \\
\hline \pm SEM & 0.7 & 0.4 & 0.5 & 0.5 & 0.4 & 0.4 & 6.8 & 0.6 & 4.6 & 0 & - & 1.4 & - & - & 0.9 \\
\hline \multicolumn{16}{|c|}{$\mathrm{LH}(\mathrm{mlU} / \mathrm{mL})$} \\
\hline Mean & 4.5 & 4.6 & 4.5 & 3.2 & 3.2 & 3.2 & 4.1 & 3.7 & 4.0 & 3.9 & 2.0 & 2.9 & 5.1 & 8.7 & 6.9 \\
\hline $\pm S E M$ & 0.6 & 0.6 & 0.4 & 0.4 & 0.3 & 0.3 & 0.7 & 0.5 & 0.5 & 1.4 & - & 1.2 & - & 一 & 1.8 \\
\hline \multicolumn{16}{|c|}{ Estradiol $(\mathrm{pg} / \mathrm{mL})$} \\
\hline Mean & 28.8 & 26.7 & 28.2 & 32.2 & 26.0 & 30.3 & 27.2 & 22.6 & 25.6 & 18.3 & 8.0 & 13.1 & 8.0 & 14.9 & 11.5 \\
\hline \pm SEM & 3.3 & 2.9 & 2.4 & 2.3 & 2.6 & 1.8 & 2.7 & 2.5 & 2.0 & 10.0 & - & 6.4 & - & - & 3.5 \\
\hline \multicolumn{16}{|c|}{ Progesterone $(\mathrm{ng} / \mathrm{dL}$ ) } \\
\hline Mean & 0.32 & 0.32 & 0.32 & 0.29 & 0.27 & 0.28 & 0.26 & 0.29 & 0.27 & 0.4 & 0.3 & 0.35 & 0.3 & 0.1 & 0.2 \\
\hline \pm SEM & 0.04 & 0.05 & 0.03 & 0.03 & 0.03 & 0.02 & 0.02 & 0.03 & 0.02 & 0.1 & - & 0.06 & - & - & 0.2 \\
\hline $\mathbf{N}$ & 27 & 12 & 39 & 25 & 11 & 36 & 22 & 11 & 33 & 3 & 1 & 4 & 1 & 1 & 2 \\
\hline
\end{tabular}

NOTE. All data are means \pm SEM. 

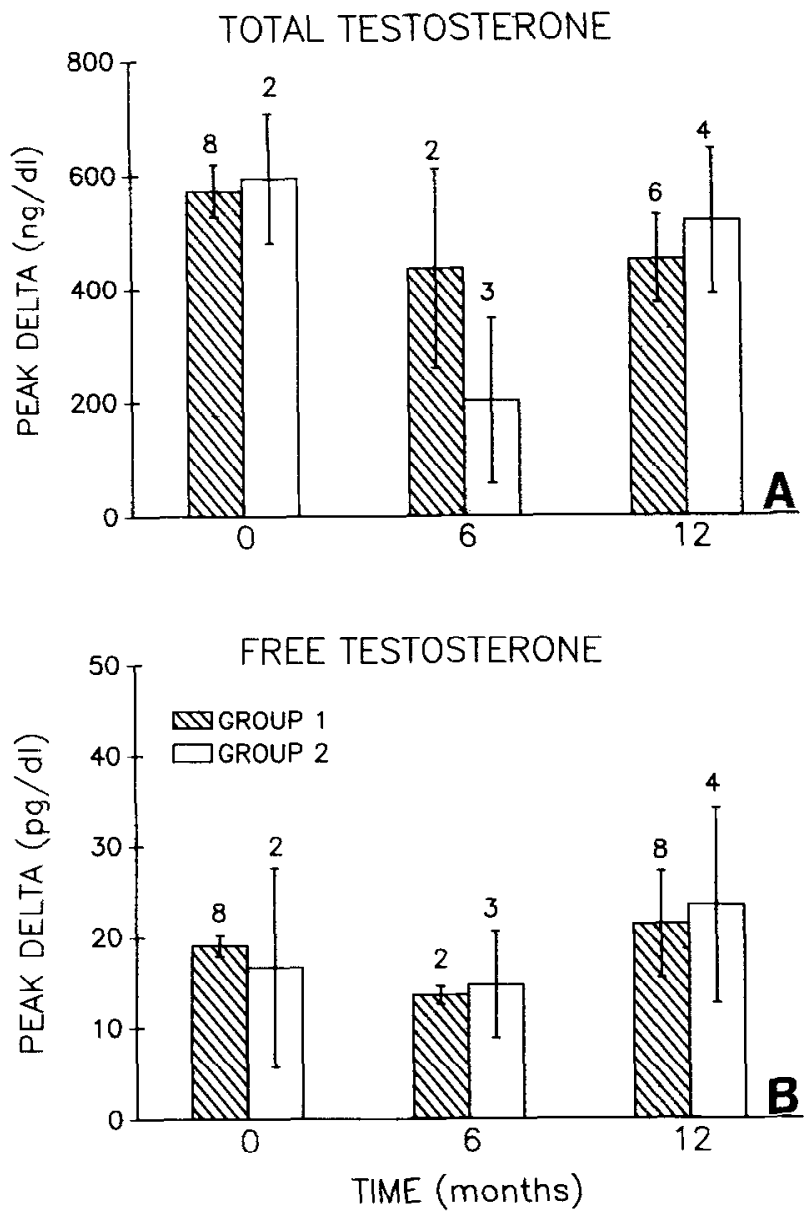

Fig 3. Maximum delta testosterone response to HCG administration. Peak delta (maximum response level minus basal concentration) plasma total (A) and free (B) testosterone responses were measured after administration of HCG $2,500 \mathrm{U}$ intramuscularly ( $\mathrm{n}=10$ at baseline, $n=5$ at 6 months, $n=10$ at 12 months).

Tissue specificity may account for the limited effect of pravastatin, since the drug induced less than a $14 \%$ inhibition of cholesterol synthesis in vivo in mouse adrenal and testis as compared with a $90 \%$ inhibition noted in the liver and ileum. ${ }^{7}$ In male Wistar rats, pravastatin (CS-514) elicited a $7.6 \%$ and $7.8 \%$ inhibition of sterol synthesis in the testis and adrenal gland, respectively. ${ }^{6}$ Similarly, pravastatin was unable to enter the intact lens of rats and was 100 -fold less inhibitory of $\left[{ }^{14} \mathrm{C}\right]$ acetate incorporation irto cholesterol in the lens compared with lovastatin or simvas$\operatorname{tatin}^{24}$

In summary, basal and Cortrosyn-stimulated cortisol and aldosterone secretion did not change during treatment with pravastatin. The secretory response of DHEA-S to corticotropin administration was impaired at 6 and 12 months; however, this effect was also noted in a control group receiving cholestyramine. Testicular function, as evaluated by basal and HCG-stimulated testosterone levels, did not change. Since the changes recorded were observed in both the pravastatin-treated patients and in those treated with
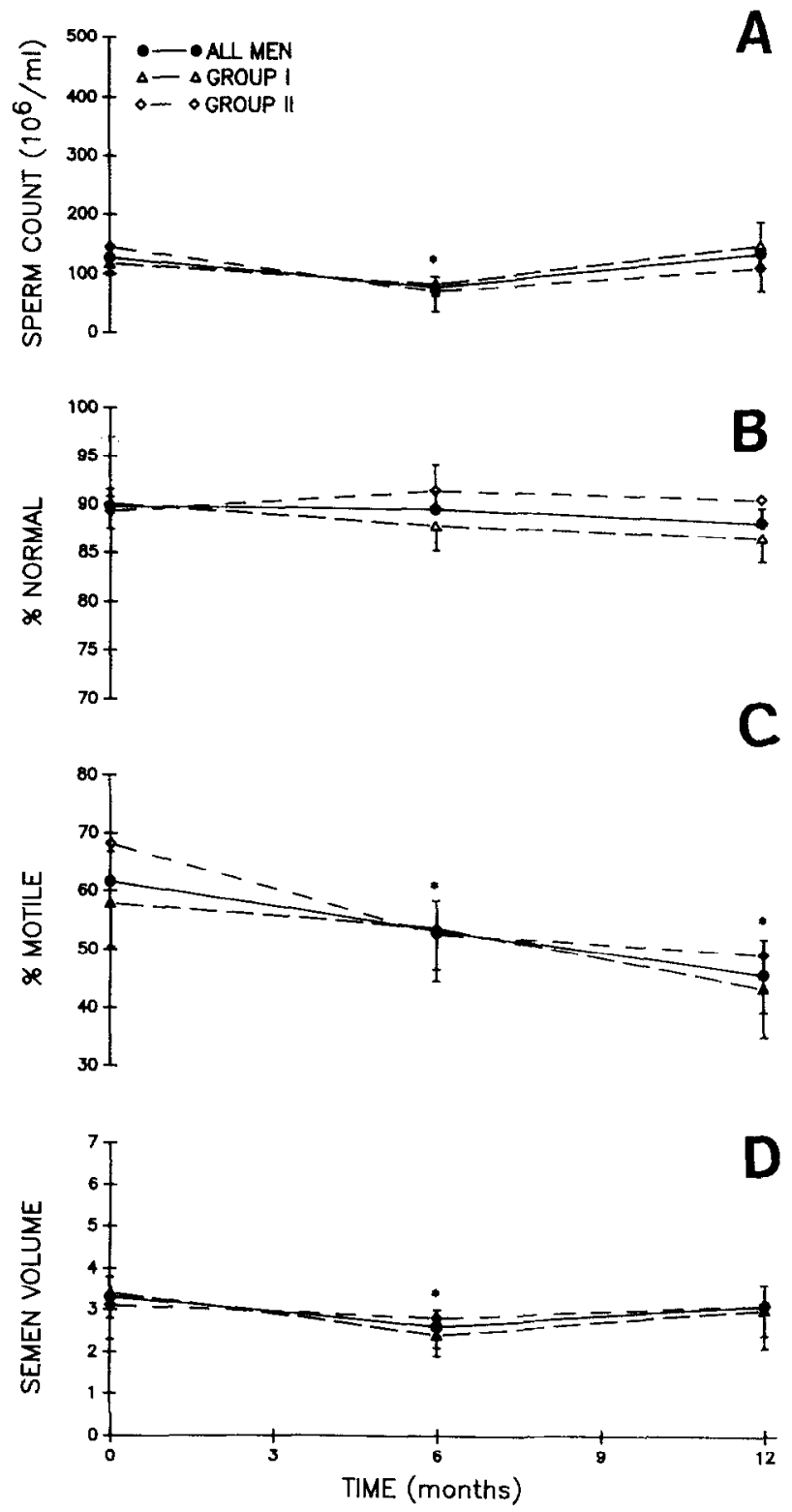

Fig 4. Semen analyses in men during 0,6 , and 12 months of lipid-lowering intervention. Data are means \pm SEM for all men as a whole and for the men in group I (pravastatin-treated) or group II (other lipid-lowering agents). (A) Sperm counts; (B) percent normal sperm; (C) percent motile; (D) semen volume. The number of subjects participating from group $I$ and $I$, respectively, at month 0 was 9 and 5 , at month 6,8 and 5 , at month 12,6 and $4 .{ }^{*} P<.05$ compared with baseline.

other lipid-lowering agents, it is possible that any impairment in steroid hormone secretion is a function of the decrease in lipid levels rather than a specific effect of HMG-CoA reductase inhibition.

\section{ACKNOWLEDGMENT}

We wish to thank Lois Chicano and Prosper Sanchez for their technical assistance and Michelle Wallace for her administrative help. 


\section{REFERENCES}

1. The Expert Panel: Report of the National Cholesterol Education Program Expert Panel on Detection, Evaluation and Treatment of High Blood Cholesterol in Adults. Arch Intern Med 148:36-69, 1988

2. Illingworth DR, Bacon S: Hypolipidemic effects of HMGCoA reductase inhibitors in patients with hypercholesterolemia. Am J Cardiol 60:33G-42G, 1987

3. Havel RJ, Hunninghake DB, Illingworth DR, et al: Lovastatin (Mevinolin) in the treatment of heterozygous familial hypercholesterolemia. Ann Intern Med 107:609-615, 1987

4. Hoeg JM, Maher MB, Zech LA, et al: Effectiveness of mevinolin on plasma lipoprotein concentrations in type II hyperlipoproteinemia. Am J Cardiol 57:933-939, 1986

5. Hunninghake DR, Knopp RH, Schonfield G, et al: Efficacy and safety of pravastatin in patients with primary hypercholesterolemia. I. A dose-response study. Atherosclerosis 85:81-89, 1990

6. Tsujita Y, Kuroda M, Shimada Y, et al: CS-514, a competitive inhibitor of 3-hydroxy-3-methylglutaryl coenzyme A reductase: Tissue-selective inhibition of sterol synthesis and hypolipidemic effect on various animal species. Biochim Biophys Acta 877:50-60, 1986

7. Koga $T$, Shimada $Y$, Kuroda $M$, et al: Tissue-selective inhibition of cholesterol synthesis in vivo by pravastatin sodium, a 3-hydroxy-3-methylglutaryl coenzyme A reductase inhibitor. Biochem Biophys Acta 1045:115-120, 1990

8. MacDonald JS, Gerson RJ, Kornrust DJ, et al: Preclinical evaluation of lovastatin. Am J Cardiol 62:16J-27J, 1988

9. Simpson ER, Carr BR, Parker CR Jr, et al: The role of serum lipoproteins in steroidogenesis by the human fetal adrenal cortex. $J$ Clin Endocrinol Metab 49:146-148, 1979

10. Illingworth DR, Lees AM, Lees RS: Adrenal cortical function in homozygous familial hypercholesterolemia. Metabolism 30:1045-1052, 1983

11. Kovanen PT, Bilheimer DW, Goldstein JL, et al: Regulatory rate for hepatic low density lipoprotein $s$ in vivo in the dog. Proc Natl Acad Sci USA 78:1194-1198, 1981

12. Fojo SS, Hoeg JM, Lackner KJ, et al: Adrenocortical function in type II hyperlipoproteinemic patients treated with lovastatin (Mevinolin). Horm Metab Res 19:648-652, 1987

13. Grundy SM, Bilheimer DW: Inhibition of 3-hydroxy-3methylglutaryl-CoA reductase by Mevinolin in familial hypercholes- terolemia heterozygotes: Effects on cholesterol balance. Proc Natl Acad Sci USA 81:2538-2542, 1984

14. Mol MJ, Stalenhoef AF, Stuyt PM, et al: Effects of inhibition of cholesterol synthesis by simvastatin on the production of adrenocortical steroid hormones and ACTH. Clin Endocrinol 31:679-689, 1989

15. Andrejs PG, Caballini L, Mazzocchi G, et al: Effects of prolonged administration of lovastatin, an inhibitor of cholesterol synthesis, on the morphology and function of rat Leydig cells. Exp Clin Endocrinol 96:15-24, 1990

16. Mastroberardino G, Costa C, Gavelli MS, et al: Plasma cortisol and testosterone in hypercholesterolaemia treated with clofibrate and lovastatin. J Int Med Res 17:388-394, 1989

17. Engelhardt H, Gore-Langton RE, Armstrong DT: Mevinolin (lovastatin) inhibits androstenedione production by porcine ovarian theca cells at the level of $17 \times$ hydroxylase:C17,20-lyase complex. Endocrinology 124:2297-2304, 1989

18. Heiss G, Tamir I, David E, et al: Lipoprotein-cholesterol distributions in selected North American populations: The Lipid Research Clinics Program prevalence study. Circulation 61:302315,1980

19. American Heart Association: Dietary Guidelines for Healthy American Adults: A statement for physicians and health professionals by the Nutrition Committee of the American Heart Association. Circulation 74:1465A, 1986 (abstr)

20. Dobs AS, Sarma PS, Wilder L: Lipid-lowering diets in patients taking pravastatin, a new HMG-CoA reductase inhibitor: Compliance and adequacy. Am J Clin Nutr 54:696-700, 1991

21. Lipid Research Clinics Program: Manual of Operation, vol 1. Lipid and Lipoproteins. Bethesda, MD, National Institutes of Health, 1974 (DHEW publication no. [NIH] 75-628)

22. Warnick GR, Albers JJ: A comprehensive evaluation of the heparin manganese precipitation procedure for estimating highdensity lipoprotein cholesterol. J Lipid Res 19:65-76, 1978

23. Friedewald WT, Levy RI, Frederickson DS: Estimation of the concentration of low-density lipoprotein cholesterol in plasma without use of the preparative ultracentrifuge. Clin Chem 18:499502,1972

24. Mosley ST, Kalinowski SS, Schafer BL, et al: Tissueselective acute effects of inhibitors of 3-hydroxy-3-methylglutaryl coenzyme A reductase on cholesterol biosynthesis in lens. J Lipid Res 30:1411-1420, 1989 